\title{
A search for ${ }^{142} \mathrm{Nd}$ evidence of primordial mantle heterogeneities in plume basalts
}

\author{
Maud Boyet, ${ }^{1,2}$ Michael O. Garcia, ${ }^{3}$ Raphaël Pik, ${ }^{4}$ and Francis Albarède ${ }^{1}$ \\ Received 29 October 2004; revised 6 December 2004; accepted 5 January 2005; published 19 February 2005.
}

[1] In order to assess whether material differentiated shortly after terrestrial accretion is still present in the deep mantle, we investigated hot spot basalts for ${ }^{142} \mathrm{Nd} /{ }^{144} \mathrm{Nd}$ anomalies that could attest for the presence of live ${ }^{146} \mathrm{Sm}$ $\left(\mathrm{T}_{1 / 2}=103 \mathrm{My}\right)$ at the time the mantle source of these basalts formed. We analyzed high ${ }^{3} \mathrm{He} /{ }^{4} \mathrm{He}$ basalts from Loihi and Ethiopia and normal ${ }^{3} \mathrm{He} /{ }^{4} \mathrm{He}$ basalts from Iceland. Although the ${ }^{143} \mathrm{Nd} /{ }^{144} \mathrm{Nd}$ ratios of these basalts reflect a source with long-term LREE (light rare earth elements) depletion, no resolvable ${ }^{142} \mathrm{Nd}$ anomalies were detected. Taking the analytical uncertainties (10-20 ppm) into account, however, the present results do not rule out the possibility that a large proportion of material fractionated very early in the Earth's history may still be hidden in the deep mantle. Citation: Boyet, M., M. O. Garcia, R. Pik, and F. Albarède (2005), A search for ${ }^{142} \mathrm{Nd}$ evidence of primordial mantle heterogeneities in plume basalts, Geophys. Res. Lett., 32, L04306, doi:10.1029/2004GL021873.

\section{Introduction}

[2] The patterns of noble gas isotope compositions in basalts are widely considered as requiring that the deep mantle is essentially undegassed [Allègre et al., 1983]. A mantle source with high ${ }^{3} \mathrm{He} /{ }^{4} \mathrm{He}$ (unradiogenic) ratios [Kurz et al., 1982] and solar Ne [Honda et al., 1991] is commonly associated with hot spots such as Hawaii or Iceland. The mantle component hosting this unradiogenic $\mathrm{He}$ and solar $\mathrm{Ne}$ is characterized by moderately depleted $\mathrm{Sr}$ and $\mathrm{Nd}$ isotopic signatures and received several more or less equivalent denominations: FOZO (for FOcal ZOne) [Hart et al., 1992], PHEM (for Primitive HElium Mantle) [Farley et al., 1992] or C (for Common) [Hanan and Graham, 1996]. In contrast, the concept that the mantle source of hot spots contains recycled oceanic crust [Hofmann and White, 1982], however, is also well entrenched. The positive correlation between $\delta^{18} \mathrm{O}$ and ${ }^{187} \mathrm{Os} /{ }^{188} \mathrm{Os}$ suggests the presence of altered basalt [Lassiter and Hauri, 1998], while $\mathrm{Sr}$ excesses have been interpreted as revealing a low-pressure gabbroic component [Sobolev et al., 2000] and the Hf- $\mathrm{Nd}-\mathrm{Pb}$ isotopic correlations in Hawaiian basalts attest to a contribution from pelagic sediments [Blichert-Toft et al., 1999]. These geochemical characteristics are consistent with tomographic

\footnotetext{
${ }^{1}$ Ecole Normale Supérieure de Lyon, Lyon, France.

${ }^{2}$ Now at Department of Terrestrial Magnetism, Carnegie Institution of Washington, Washington, DC, USA.

${ }^{3}$ Department of Geology and Geophysics, University of Hawaii, Honolulu, Hawaii, USA.

${ }^{4}$ Centre de Recherches Pétrographiques et Géochimiques, Vandoeuvre, France.
}

Copyright 2005 by the American Geophysical Union. 0094-8276/05/2004GL021873 evidence that some subducted plates reach the core-mantle boundary [Grand et al., 1997; van der Hilst et al., 1997].

[3] The ${ }^{146} \mathrm{Sm}^{-}{ }^{142} \mathrm{Nd}$ system with its half-life of $103 \mathrm{My}$ also has the potential of identifying primordial heterogeneities in the Earth's mantle. Both the parent and daughter nuclides are refractory and lithophile rare earth elements (REE). They did not fractionate during accretion and core segregation. We contend that high ${ }^{3} \mathrm{He} /{ }^{4} \mathrm{He}$ ratios does not necessarily signal material with chondritic abundances and therefore that the ${ }^{146} \mathrm{Sm}_{-}{ }^{142} \mathrm{Nd}$ system complements ${ }^{3} \mathrm{He} /{ }^{4} \mathrm{He}$ evidence. The liberation of the gravitational energy from the accretion and core formation and from the heat of the extinct radioactive nuclides ${ }^{26} \mathrm{Al}$ and ${ }^{60} \mathrm{Fe}$ on a time scale of a few My triggered the wholesale melting of the Earth's mantle, at least down to a certain depth in the upper mantle. On top of the molten mantle, a buoyant conductive lithosphere of hydrous minerals, notably serpentine, strongly reduced heat escape from the magma [Boyet et al., 2003]. At the high pressures of the melt/cumulate interface, $\mathrm{CO}_{2}$ and $\mathrm{H}_{2} \mathrm{O}$ solubility is so high that no gas phase can evolve which would strip He from the melt. Gases in general and ${ }^{3} \mathrm{He}$ in particular distribute themselves among the coexisting solid and liquid phases just as any other incompatible elements such as Th or Nd. Although the persistence of ${ }^{142} \mathrm{Nd}$ anomalies needs very early $\mathrm{Sm} / \mathrm{Nd}$ magmatic fractionation, ${ }^{3} \mathrm{He}$ should still be ubiquitous in the undegassed material. For example, a silicate/melt fractionation event taking place at the time of core formation $30 \mathrm{My}$ after the isolation of the Solar Nebula [Kleine et al., 2002; Yin et al., 2002] capable of creating a typical anomaly of $+1000 \mathrm{ppm}(+10 \varepsilon)$ on the ${ }^{143} \mathrm{Nd} /{ }^{144} \mathrm{Nd}$ ratio in the modern mantle would also create a $20 \mathrm{ppm}$ anomaly on its ${ }^{142} \mathrm{Nd} /{ }^{144} \mathrm{Nd}$ ratio. Such ${ }^{142} \mathrm{Nd}$ anomalies are resolvable by modern mass spectrometry techniques.

[4] The existence of ${ }^{142} \mathrm{Nd}$ anomalies and therefore of live ${ }^{146} \mathrm{Sm}$ at the time of wholesale differentiation of the planetary mantle is well documented in eucrites (up to 300 ppm) [Prinzhofer et al., 1992; Wadhwa and Lugmair, 1996], Martian meteorites (100 ppm) [Harper et al., 1995], and even lunar samples (30 ppm) [Nyquist et al., 1995]. The ${ }^{142} \mathrm{Nd}$ anomalies reported in Archean samples also attest to the fact that the terrestrial mantle went through a major $\mathrm{Sm} /$ $\mathrm{Nd}$ fractionation event within a few tens of My after planetary accretion [Boyet et al., 2003; Caro et al., 2003; Harper and Jacobsen, 1992]. All the ${ }^{142} \mathrm{Nd}$ terrestrial anomalies detected are positive and so far have been exclusively observed in $3.8 \mathrm{Gyr}$ samples from the Isua Supracrustal Belt (West Greenland). Therefore, $600 \mathrm{My}$ after the beginning of the Earth's accretion, this primordial reservoir had not been completely remixed with the rest of the mantle in spite of the Archean mantle being hotter and mantle convection stronger than today. Here we present new 
Table 1. ${ }^{142} \mathrm{Nd}$ and ${ }^{143} \mathrm{Nd}$ isotopic data for Iceland, Ethiopia and Loihi (Hawaiian Volcano) samples ${ }^{\mathrm{a}}$

\begin{tabular}{|c|c|c|c|c|c|c|}
\hline Sample & Type & $\mathrm{Mg \#}$ & ${ }^{3} \mathrm{He} /{ }^{4} \mathrm{He}$ & $\mathrm{N}$ & $\varepsilon_{142 \mathrm{Nd}} \pm 2 \sigma_{\mathrm{m}}$ & $\varepsilon_{143 \mathrm{Nd}} \pm 2 \sigma_{m}$ \\
\hline \multicolumn{7}{|c|}{ Iceland } \\
\hline 9323 & aph. bas. & $55.70]$ & & 3 & $0.24 \pm 0.17$ & $8.06 \pm 0.15$ \\
\hline 9244 & aph. bas. & 53.40 & & 5 & $0.18 \pm 0.14$ & $7.79 \pm 0.13$ \\
\hline 9356 & picrite & 71.60 & & 3 & $-0.05 \pm 0.17$ & $9.04 \pm 0.13$ \\
\hline 9376 & picrite & 61.60 & $8-10$ & 4 & $0.06 \pm 0.12$ & $9.08 \pm 0.12$ \\
\hline 9377 & picrite & 65.30 & & 5 & $0.07 \pm 0.11$ & $9.64 \pm 0.09$ \\
\hline 9381 & picrite & 76.30 & & 5 & $-0.07 \pm 0.14$ & $9.56 \pm 0.11$ \\
\hline 9390 & picrite & 78.90 & & 4 & $-0.03 \pm 0.12$ & $10.12 \pm 0.10$ \\
\hline 9394 & picrite & 68.80 & & 1 & $-0.18 \pm 0.20$ & $10.00 \pm 0.17$ \\
\hline \multicolumn{7}{|c|}{ Ethiopia } \\
\hline E38 & HT2 & 68.74 & 16.4 & 2 & $0.03 \pm 0.18$ & $6.01 \pm 0.14$ \\
\hline E39 & HT2 & - & 19.6 & 6 & $-0.07 \pm 0.13$ & $5.91 \pm 0.12$ \\
\hline E95 & LT & 39.23 & - & 6 & $0.02 \pm 0.14$ & $4.78 \pm 0.11$ \\
\hline E156 & alk. bas. & - & 9.9 & 3 & $0.12 \pm 0.15$ & $5.85 \pm 0.12$ \\
\hline E181 & LT & - & - & 3 & $-0.08 \pm 0.19$ & $4.60 \pm 0.16$ \\
\hline E202 & LT & 50.99 & - & 5 & $-0.05 \pm 0.11$ & $2.10 \pm 0.10$ \\
\hline E216 & LT & 60.19 & - & 5 & $-0.07 \pm 0.14$ & $8.25 \pm 0.11$ \\
\hline E266 & alk. bas. & - & 13.2 & 4 & $-0.07 \pm 0.17$ & $3.85 \pm 0.13$ \\
\hline E268 & alk. bas. & - & 16.9 & 4 & $-0.03 \pm 0.19$ & $3.32 \pm 0.16$ \\
\hline $\mathrm{E} 271$ & alk. bas. & - & 15.7 & 2 & $-0.07 \pm 0.16$ & $2.69 \pm 0.14$ \\
\hline \multicolumn{7}{|c|}{ Loihi (Hawaii) } \\
\hline $158-4$ & basanitoid & - & & 4 & $0.01 \pm 0.12$ & $6.74 \pm 0.11$ \\
\hline $1801-5$ & tholeiite & $56.25]$ & & 6 & $0.06 \pm 0.13$ & $5.87 \pm 0.11$ \\
\hline $1801-19$ & tholeiite & 55.77 & $22-35$ & 6 & $-0.08 \pm 0.12$ & $6.16 \pm 0.10$ \\
\hline $1802-4 b$ & alk. bas. & 46.25 & & 3 & $-0.08 \pm 0.10$ & $6.15 \pm 0.08$ \\
\hline $1804-1$ & tholeiite & 58.51 & & 6 & $0.09 \pm 0.09$ & $6.04 \pm 0.08$ \\
\hline $1804-21$ & trans. bas. & 57.17 & & 9 & $0.00 \pm 0.08$ & $6.03 \pm 0.07$ \\
\hline
\end{tabular}

a Sample compositions giving rock types and $\mathrm{Mg \#}$ values are from Stracke et al. [2003] for Iceland, Pik et al. [1998] for Ethiopia, and Garcia et al. [1995] for Loihi. ${ }^{3} \mathrm{He} /{ }^{4} \mathrm{He}$ ratios are from Breddam et al. [2000] for Iceland, Marty et al. [1996] for Ethiopia, and Kurz et al. [1983] for Loihi. LT and HT2 refer to low-Ti and high-Ti basalts, respectively. The measurements were carried out on the Lyon VG Plasma 54 MC-ICPMS. $\mathrm{N}$ is the number of measurements. The $\mathrm{Nd}$ isotopic ratios were normalized for mass fractionation using ${ }^{146} \mathrm{Nd} /{ }^{144} \mathrm{Nd}=0.7219$. $\left.\varepsilon_{142 \mathrm{Nd}}-\left\{\left({ }^{142} \mathrm{Nd} /{ }^{144} \mathrm{Nd}\right)_{\text {sample }}\left({ }^{142} \mathrm{Nd} /{ }^{144} \mathrm{Nd}\right)_{\text {standard }}-1\right)\right\} \times 10^{4}$ where $\left({ }^{142} \mathrm{Nd} /{ }^{144} \mathrm{Nd}\right)_{\text {standard }}$ refers to the JMC standard (batch $\left.801149 \mathrm{~A}\right)$ analyzed before the sample. $\mathrm{Ce}$ and $\mathrm{Sm}$ isobaric interferences were monitored at masses 140 and 147 , respectively. The $\varepsilon_{143 \mathrm{Nd}}$ values are calculated with respect to CHUR with a modern value of 0.512638 . The final precision quoted for $\varepsilon_{142 \mathrm{Nd}}$ and $\varepsilon_{143 \mathrm{Nd}}$ for each sample corresponds to the weighted internal precisions $\left(2 \sigma_{\mathrm{m}}\right)$ of both the sample and standard runs.

${ }^{142} \mathrm{Nd}$ isotopic data for samples collected from three wellcharacterized sites that each represents the expression of a mantle plume: (1) Loihi volcano, an extensively studied occurrence of oceanic hot spot volcanism, (2) Iceland, a hot spot located on the mid-Atlantic ridge, and (3) Ethiopian continental flood basalts (see auxiliary material ${ }^{1}$ ). In order to minimize potential crustal contamination, a problem for more fractionated Icelandic lava [Eiler et al., 2000], we selected samples with high $\mathrm{MgO}$ contents. Caro et al. [2003] found, as expected from the long-term geodynamic processing of the upper mantle, that mid-ocean ridge basalts show no ${ }^{142} \mathrm{Nd}$ anomaly. We will show that hot spot basalts, even those with the highest ${ }^{3} \mathrm{He} /{ }^{4} \mathrm{He}$ ratios, also have chondritic ${ }^{142} \mathrm{Nd}$ isotopic abundances.

\section{Results}

[5] All details of the chemical separation and mass spectrometry techniques are described elsewhere [Boyet et

${ }^{1}$ Auxiliary material is available at ftp://ftp.agu.org/apend/gl/ 2004GL021873. $a l ., 2003]$. The Nd isotope compositions were measured by multiple-collector inductively coupled plasma mass spectrometry (MC-ICPMS) in Lyon. Work on Isua mantlederived material demonstrated that by pooling data on the same samples, anomalies of $<20$ ppm ( $0.2 \varepsilon$-units $)$ can be clearly resolved by this technique [Boyet et al., 2003]. The

${ }^{142} \mathrm{Nd}$ isotopic data are reported in Table 1 and displayed in Figure 1. None of the samples analyzed here show a resolvable ${ }^{142} \mathrm{Nd}$ anomaly: the values of $\varepsilon_{142 \mathrm{Nd}}$ fall between -0.18 and +0.24 . The unweighted mean of $\varepsilon_{142 \mathrm{Nd}}$ values for all the samples analyzed in the present study is $0.00 \pm$ 0.20 (2-standard deviations). Sample 9323 from Iceland has the largest deviation $(+0.24)$ but this analysis has not been replicated on separate dissolutions and the mean value is dominated by one of the three measurements, which has an $\varepsilon_{142 \mathrm{Nd}}$ of $+0.51 \pm 0.34$. Routine standard error $\left(2 \sigma_{\mathrm{m}}\right)$ on $\varepsilon_{142 \mathrm{Nd}}$ is $10-20 \mathrm{ppm}$. Therefore, all the sample ${ }^{142} \mathrm{Nd} /{ }^{144} \mathrm{Nd}$ ratios are chondritic within error bars. The Icelandic samples show the largest scatter, which can be explained by the particularly low Nd contents of picrites [Slater, 1996; Stracke et al., 2003]. The $\varepsilon_{143 \mathrm{Nd}}$ values range between +8 and +10 for the Icelandic samples, between +5 and +6 for Loihi, and between +2 and +6 for Ethiopia.

\section{Discussion}

[6] The present results show that, although the mantle sources of the studied basalts have positive $\varepsilon_{143 \mathrm{Nd}}$ values reflecting a source with long-term LREE depletion, no

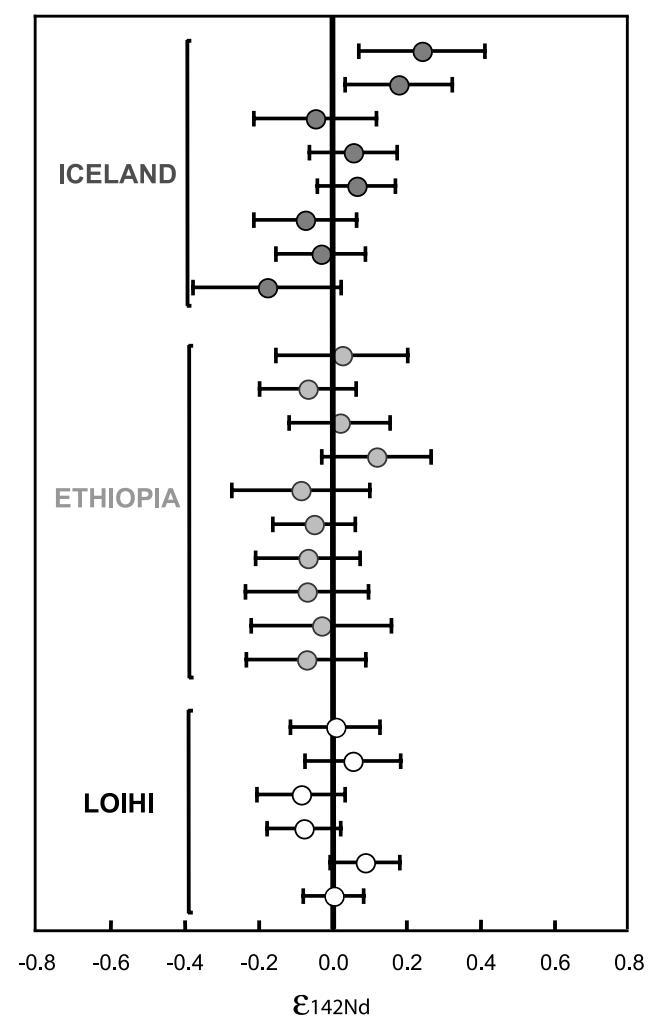

Figure 1. Representation of ${ }^{142} \mathrm{Nd} /{ }^{144} \mathrm{Nd}$ ratios expressed as $\varepsilon_{142 \mathrm{Nd}}$ of hot spot samples listed in Table 1. This plot displays all the values used to derive the mean isotope compositions listed in Table 1 with samples organized by locality. 


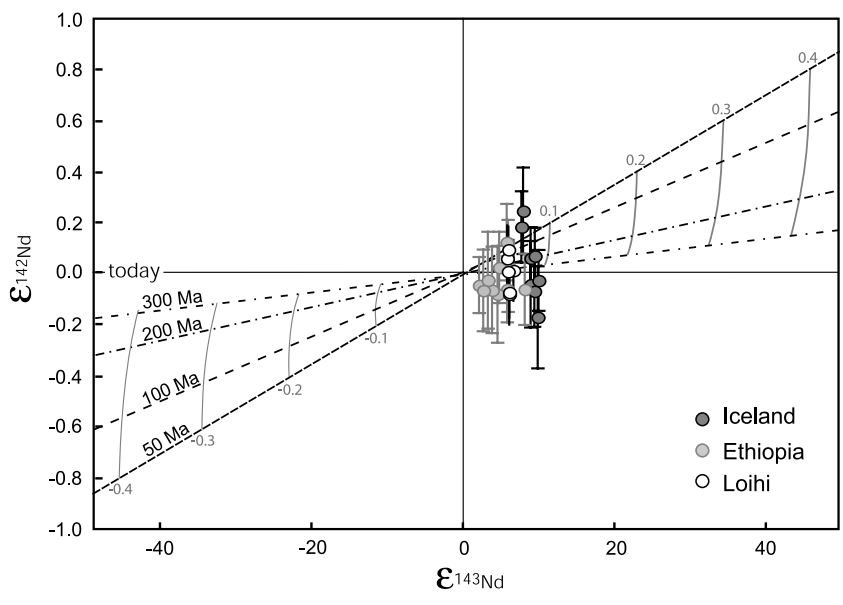

Figure 2. Different evolution trajectories of the $\mathrm{Nd}$ isotopic composition for a chondritic reservoir (equivalent to the BSE) fractionated very early in the history of the Solar System using a simple two-stage model evolution. The first stage starts at $T_{0}$ with planetary accretion and undifferentiated chondritic material, the second stage at $T_{0}+$ $\Delta T$ with the wholesale differentiation of the mantle (equations (1) and (2)). The value of $\varepsilon_{142 \mathrm{Nd}}$ in each reservoir strongly depends on the time interval $\Delta T$ (black lines) and the corresponding parent-daughter fractionation factor $f_{\mathrm{Sm} / \mathrm{Nd}}$ (grey curves). For closed-system evolution of the two parent-daughter pairs, the top right quadrant represents a depleted reservoir with a $\mathrm{Sm} / \mathrm{Nd}$ ratio lower than the CHUR value. The bottom left quadrant defines the complementary enriched reservoir $(\mathrm{Sm} / \mathrm{Nd}$ lower than to the CHUR value). The error bars correspond to the weighted internal precision (2-sigma errors) on each measurement and, for $\varepsilon_{143 \mathrm{Nd}}$, are smaller than the size of the symbols.

${ }^{142} \mathrm{Nd}$ anomaly can be resolved. Although measurable ${ }^{142} \mathrm{Nd}$ anomalies have been observed in Isua metabasalts, mantle convection over the last 3.8 Gy seems to have obliterated all memory of the mantle primordial differentiation. Simple models may account for the present data:

[7] 1. The terrestrial magma ocean never formed. Because of its strong gravity and abundant water, the Earth could not evolve a buoyant crust of anorthosite acting as an insulating boundary layer. Heat from accretion and radioactivity was radiated into space, the cold heavy crust foundered into molten magma, and melt quickly vanished [Davies, 1990]. This model neglects the presence of the hydrosphere, the ensuing hydration of the upper layer, and the formation of a buoyant hydrous lithosphere [Boyet et al., 2003].

[8] 2. Contrary to the mantle of Mars and Moon, mineral segregation from the magma ocean produced too little $\mathrm{Sm} / \mathrm{Nd}$ fractionation. This is unlikely since both majorite cumulates and the lithosphere should be prominently fractionated in the magma ocean.

[9] 3. The ${ }^{142} \mathrm{Nd}$ anomalies observed in Isua metabasalts reveal local phenomena and not the wholesale differentiation of the mantle. The existing ${ }^{142} \mathrm{Nd}$ data are still too fragmentary for such a possibility to be assessed.

[10] 4. Material differentiated in the first 10's of My of the Earth's history is remixed and interlayered with material reprocessed afterwards. Upon melting and extraction of hot spot basalts into their volcanic system, mixing occurs. The mixture $\mathrm{Nd}$ is dominated by the recycled end-member whereas $\mathrm{He}$ and $\mathrm{Ne}$ are dominated by primitive undegassed end-member.

[11] We consider model 4 as the most likely but contend that the existence of primordial heterogeneities in the mantle source of hot spot basalts is not ruled out by the present observations. A faint hint at ${ }^{142} \mathrm{Nd}$ isotopic heterogeneities may be the broad dispersion of the raw $\varepsilon_{142 \mathrm{Nd}}$ data $( \pm 0.20)$ with respect to the mean analytical error $( \pm 0.12)$ at the same 95 confidence level. The $\varepsilon_{142 \mathrm{Nd}}-\varepsilon_{143 \mathrm{Nd}}$ diagram of Figure 2 shows the evolution trajectories of the $\mathrm{Nd}$ isotopic composition for a chondritic reservoir (equivalent to the Bulk Silicate Earth) fractionated very early in the history of the Solar System using a simple two-stage model evolution. The ${ }^{142} \mathrm{Nd}-{ }^{143} \mathrm{Nd}$ isotopic signature of this fractionated reservoir depends on two main parameters, the relative parent/daughter fractionation factor $f_{\mathrm{Sm} / \mathrm{Nd}}$ with respect to chondrites and the age of this event. The two-stage model describes the evolution of a chondritic mantle undergoing $\mathrm{Sm} / \mathrm{Nd}$ fractionation at time $\Delta T$ after accretion. If $T_{0}$ is the age of the Earth, the modern $\varepsilon_{143 \mathrm{Nd}}$ and $\varepsilon_{142 \mathrm{Nd}}$ values of the mantle are given by [Harper and Jacobsen, 1992]:

$$
\begin{gathered}
\varepsilon_{143 \mathrm{Nd}} \approx Q_{143} f_{\mathrm{Sm} / \mathrm{Nd}} T_{0} \\
\varepsilon_{142 \mathrm{Nd}} \approx Q_{142} f_{\mathrm{Sm} / \mathrm{Nd}}\left({ }^{146} \mathrm{Sm} /{ }^{144} \mathrm{Sm}\right) \times e^{-\lambda \Delta T}
\end{gathered}
$$

where $Q_{143}=25.09 \mathrm{~Gy}^{-1}, Q_{142}=353,\left({ }^{146} \mathrm{Sm} /{ }^{144} \mathrm{Sm}\right){ }_{\text {To }}^{\text {CHUR }}=$ 0.008 [Prinzhofer et al., 1992] and $\lambda$ stands for the decay constant of ${ }^{146} \mathrm{Sm}\left(6.73 \mathrm{Ga}^{-1}\right)$. Fractionation events younger than $\sim 4.25 \mathrm{Ga}$ or with $\mathrm{Sm} / \mathrm{Nd}$ fractionation $<10$ percent produce $\varepsilon_{142 \mathrm{Nd}}$ values indistinguishable from the BSE value within the typical analytical uncertainties of the techniques used in this work $\left(\varepsilon_{142 \mathrm{Nd}} \approx 0.0 \pm 0.15\right)$. In comparison, the highest anomaly reported so far on terrestrial samples is of $+0.3 \varepsilon$ [Boyet et al., 2003; Harper and Jacobsen, 1992].

[12] Simulations tracking chemical tracers in convection models of the mantle suggest that primordial material formed during the initial mantle differentiation may have survived unmodified to the present day [Davies, 2002; Xie and Tackley, 2004]. Such a possibility has long been discounted on the basis that mantle convection would quickly homogenize the mantle and wipe out any primordial signal [O'Nions and Tolstikhin, 1996]. This is only true for the mean primordial signature of the primitive mantle and convective mixing will not obliterate all the remnants of primitive material in the lower mantle. If the mantle is a well-mixed reservoir, the probability that an atom is extracted at a given time is independent of its history in the reservoir (Poisson process). In this case, the residence times are distributed exponentially and the proportion of $4.56 \mathrm{Ga}$ old $\mathrm{Nd}$ in a system with a 7 Gy mean residence time typical of $\mathrm{Nd}$ (F. Albarede, The survival of mantle geochemical heterogeneities, submitted to Structure, Composition, and Evolution of Earth's Mantle, Geophysisical Monograph Series, edited by R. van der Hilst et al., AGU, Washington, D. C.) is simply exp $(-4.56 / 7)$ or about 50 percent. If the reservoir is not well mixed and old undegassed material lingers at the base of the mantle, the proportion of primordial material may be even larger [Gurnis and Davies, 1986]. Even in modest proportions, a 
primordial component could therefore impart the high ${ }^{3} \mathrm{He} /{ }^{4} \mathrm{He}$ value and the solar Ne signature to oceanic basalts which are otherwise characterized by the recycled character of their lithophile isotopic systems.

\section{Conclusion}

[13] We have shown that although the mantle sources of the basalts studied here have positive $\varepsilon_{143 \mathrm{Nd}}$ values reflecting a source with long-term LREE depletion, no resolvable ${ }^{142} \mathrm{Nd}$ anomaly is detectable in these hot spot samples. The analytical precision does not however exclude the presence of material fractionated very early in the Earth's history in the mantle source of hot spots especially if this component is interspersed with material processed much later in the Earth's history.

[14] Acknowledgments. We are grateful to Philippe Télouk for keeping the Plasma 54 in working conditions and to Janne Blichert-Tof for constant feedback in the lab. Dan McKenzie is thanked for providing the Theistareykir samples and for encouragement. Comments by two anonymous reviewers helped improve the readability of the manuscript. This work was supported by the Institut National des Sciences de l'Univers, in particular through the Program "Intérieur de la Terre" to FA, and by National Science Foundation grant 0336874 to MG.

\section{References}

Allègre, C. J., T. Staudacher, P. Sarda, and M. Kurz (1983), Constraints on evolution of Earth's mantle from rare gas systematics, Nature, 303, $762-$ 766.

Blichert-Toft, J., F. A. Frey, and F. Albarède (1999), Hf isotope evidence for pelagic sediments in the source of Hawaiian basalts, Science, 285, 879882 .

Boyet, M., J. Blichert-Toft, M. Rosing, M. Storey, P. Télouk, and F. Albarède (2003), ${ }^{142} \mathrm{Nd}$ evidence for early Earth differentiation, Earth Planet. Sci. Lett., 214, 427-442.

Breddam, K., M. D. Kurz, and M. Storey (2000), Mapping out of the conduit of the Iceland mantle plume with helium isotopes, Earth Planet. Sci. Lett., 176, 45-55.

Caro, C., B. Bourdon, J. L. Birck, and S. Moorbath (2003), ${ }^{146} \mathrm{Sm}^{-142} \mathrm{Nd}$ evidence from Isua metamorphosed sediments for early differentiation of the Earth's mantle, Nature, 423, 428-432.

Davies, G. F. (1990), Heat and mass transport in the early Earth, in Origin of the Earth, edited by H. E. Newsom and J. H. Jones, pp. 175-194, Oxford Univ. Press, New York.

Davies, G. F. (2002), Stirring geochemistry in mantle convection models with stiff plates and slabs, Geochim. Cosmochim. Acta, 66, 3125-3142.

Eiler, J. M., K. Gronvold, and N. Kitchen (2000), Oxygen isotope evidence for the origin of chemical variations in lavas from Theistareykir volcano in Iceland's northern volcanic zone, Earth Planet. Sci. Lett., 184, 269286.

Farley, K. A., J. H. Natland, and H. Craig (1992), Binary mixing of enriched and undegassed (primitive?) mantle components ( $\mathrm{He}, \mathrm{Sr}, \mathrm{Nd}, \mathrm{Pb}$ ) in Samoan lavas, Earth Planet. Sci. Lett., 111, 183-199.

Garcia, M. O., D. J. P. Foss, H. B. West, and J. J. Mahoney (1995), Geochemical and isotopic evolution of Loihi volcano, Hawaii, J. Petrol, $36,1647-1674$.

Grand, S. P., R. D. Van der Hilst, and S. Widiyantoro (1997), High resolution global tomography: A snapshot of convection in the Earth, Geol. Soc. Am. Today, 7, 1-7.

Gurnis, M., and G. F. Davies (1986), The effect of depth-dependent viscosity on convective mixing in the mantle and the possible survival of primitive mantle, Geophys. Res. Lett., 13, 541-544.

Hanan, B. B., and D. W. Graham (1996), Lead and helium isotope evidence from oceanic basalts for a common deep source of mantle plumes, Science, 272, 991-995.
Harper, C. L., and S. B. Jacobsen (1992), Evidence from coupled ${ }^{14} \mathrm{Sm}^{143} \mathrm{Nd}$ and ${ }^{146} \mathrm{Sm}-{ }^{142} \mathrm{Nd}$ systematics for very early (4.5-Gyr) differentiation of the Earth's mantle, Nature, 360, 728-732.

Harper, J. C. L., L. E. Nyquist, B. Bansal, H. Wiesmann, and C.-Y. Shih (1995), Rapid accretion and early differentiation of Mars indicated by ${ }^{142} \mathrm{Nd} /{ }^{144} \mathrm{Nd}$ in SNC meteorites, Science, 267, 213-217.

Hart, S. R., E. H. Hauri, L. A. Oschmann, and J. A. Whitehead (1992), Mantle plumes and entrainment: Isotopic evidence, Science, 256, 517520 .

Hofmann, A. W., and W. M. White (1982), Mantle plumes from ancient oceanic crust, Earth Planet. Sci. Lett., 57, 421-436.

Honda, M., I. McDougall, D. B. Patterson, A. Doulgeris, and D. Clague (1991), Possible solar noble-gas component in Hawaiian basalts, Earth Planet. Sci. Lett., 349, 149-151.

Kleine, T., C. Münker, K. Mezger, and H. Palme (2002), Rapid accretion and early core formation on asteroids and the terrestrial planets from Hf-W chronometry, Nature, 418, 952-955.

Kurz, M. D., W. J. Jenkins, and S. R. Hart (1982), Helium isotopic systematics of oceanic islands and mantle heterogeneity, Nature, 297, $43-47$.

Kurz, M. D., W. J. Jenkins, S. R. Hart, and D. Clague (1983), Helium isotopic variations in volcanic rocks from Loihi seamount and the Island of Hawaii, Earth Planet. Sci. Lett., 66, 388-406.

Lassiter, J. C., and E. H. Hauri (1998), Osmium-isotope variations in Hawaiian lavas: Evidence for recycled oceanic lithosphere in the Hawaiian plume, Earth Planet. Sci. Lett., 164, 483-496.

Marty, B., R. Pik, and Y. Gezahegn (1996), Helium isotopic variations in Ethiopian plume lavas: Nature of magmatic sources and limit on lower mantle contribution, Earth Planet. Sci. Lett., 144, 223-237.

Nyquist, L. E., H. Wiesman, B. Bansal, C.-Y. Shih, J. E. Keith, and C. L. Harper (1995), ${ }^{146} \mathrm{Sm}^{142} \mathrm{Nd}$ formation interval for the lunar mantle material, Geochim. Cosmochim. Acta, 59, 2817-2837.

O’Nions, R. K., and L. N. Tolstikhin (1996), Limits on the mass flux between lower and upper mantle and stability of layering, Earth Planet. Sci. Lett., 139, 213-222.

Pik, R., C. Deniel, C. Coulon, G. Yirgu, C. Hofmann, and Ayalew (1998), The northwestern Ethiopian Plateau flood basalts: Classification and spatial distribution of magmas types, J. Volcanol Geotherm. Res., 81, $91-111$.

Prinzhofer, A., D. A. Papanastassiou, and G. J. Wasserburg (1992), Samarium-neodymium evolution of meteorites, Geochim. Cosmochim. Acta, 56, 797-815.

Slater, L. (1996), Melt generation beneath Iceland, Ph.D. thesis, 221 pp., Univ. of Cambridge, Cambridge, UK.

Sobolev, A. V., A. W. Hofmann, and I. K. Nikogosian (2000), Recycled oceanic crust observed in 'ghost plagioclase' within the source of oceanic lavas, Nature, 404, 986-990.

Stracke, A., A. Zindler, V. J. M. Salters, D. McKenzie, J. Blichert-Toft, F. Albarède, and K. Grönvold (2003), Theistareykir revisited, Geochem. Geophys. Geosyst., 4(2), 8507, doi:10.1029/2001GC000201.

van der Hilst, R. D., S. Widiyantoro, and E. R. Engdahl (1997), Evidence for deep mantle circulation from global tomography, Nature, 386, 578584.

Wadhwa, M., and G. W. Lugmair (1996), Age of the eucrite "Caldera" from convergence of long-lived and short-lived chronometers, Geochim. Cosmochim. Acta, 60, 4889-4893.

Xie, S., and P. J. Tackley (2004), Evolution of helium and argon isotopes in a convecting mantle, Phys. Earth Planet. Inter., 146, 417-439.

Yin, Q., S. B. Jacobsen, K. Yamashita, B.-T. J. P. Télouk, and F. Albarède (2002), A short timescale for terrestrial planet formation from $\mathrm{Hf}-\mathrm{W}$ chronometry of meteorites, Nature, 418, 949-952.

F. Albarède, Ecole Normale Supérieure de Lyon, F-69364 Lyon Cedex 07, France.

M. Boyet, Department of Terrestrial Magnetism, Carnegie Institution of Washington, 5241 Broad Branch Rd. NW, Washington, DC 20015, USA. (boyet@dtm.ciw.edu)

M. O. Garcia, Department of Geology and Geophysics, University of Hawaii, Honolulu, HI 96822, USA.

R. Pik, CRPG, F-54501 Vandoeuvre Cedex, France. 